\title{
THE EFFECTS OF PETTLEP AND TRADITIONAL IMAGERY INTERVENTIONS ON NETBALL PLAYERS SHOOTING ACCURACY
}

\author{
Adilah Mohammad Mazli, Thariq Khan Azizuddin Khan \& Ahmad Hashim \\ Fakulti Sains Sukan dan Kejurulatihan, Universiti Pendidikan Sultan Idris, \\ Tanjong Malim, Perak, Malaysia
}

Jurnal Sains Sukan dan Pendidikan Jasmani 7(2): 56-64, Received: 10 September 2018, Accepted: 1 October 2018

\begin{abstract}
The purpose of this study was to examine the effects of the Physical, Environment, Task, Timing, Learning, Emotion and Perspective (PETTLEP) and traditional imagery interventions on netball players shooting accuracy. In this study, 48 netball players from Larut Matang and Selama district in Perak were invited to participate. They were tested on imagery ability and divided into three interventions groups consisting, the PETTLEP audio imagery, the PETTLEP audio video imagery and the traditional written imagery script. The participants in the PETTLEP audio and audio video interventions imagery employed the interventions at the netball court. Conversely, the participants in the traditional written imagery scrip group employed the interventions at their own houses. All participants conducted their imagery training based on the imagery training schedule that was provided to them. The imagery training duration was around 30 minutes and scheduled for three times per week for four weeks. The pre-test intervention and post-test study design were employed in this study. The paired t-test results indicated that there were significant differences on the pre and post test data for netball shooting accuracy for both participants in PETTLEP groups, however there was no significant differences were found in the traditional written imagery script group. Furthermore, the One Way ANOVA results indicated that there were significant differences on the data of post-test among both PETTLEP groups compared to the traditional groups. However, there were no significant differences found between PETTLEP groups. The findings showed that the participants in the PETTLEP imagery interventions showed better accuracy netball shooting compared to the participants in the traditional intervention group, however both audio and combination audio and video PETLLEP interventions enhanced similar netball shooting performances. In conclusion, from this study the PETTLEP imagery model was found to improve players' performance, especially when it was combined with audio imagery and video modelling.
\end{abstract}

Keywords: Imagery, PETTLEP, traditional, video and audio 


\section{INTRODUCTION}

Imagery is a mental process that uses most or all of the senses to create or replicate the experience in mind (Vealey \& Greenleaf, 2009). The program accompanied by psychological interventions especially imagery has proven that imagery is an effective and important technique for improving performance and achievement compared to the other mental training. Furthermore, there are researches findings suggests that the imagery is an important psychological skill (Nordin \& Cumming, 2008). Many researchers have found that the characteristics of the imagery and training procedures are predominant factors that can influence sports performance (Short, Bruggeman, Engel, Marback, Wang \& Willadsen, 2002; Vealey \& Greenleaf, 2009). Based on what has been stated above, there are few established procedures how the imagery can be used effectively (Wakefield \& Smith, 2012).

For example, the PETTLEP (Physical, Environment, Task, Timing, Learning, Emotion and Perspective). Imagery is a training model that was developed by Holmes and Collins (2001) provided a set of guidelines for the use of imagery in sports situations. Specifically, the PETTLEP is an acronym where by each letter represents important factors that need to be considered before developing imagery intervention. According to Wakefield and Smith (2012), PETTLEP model of imagery is based on research findings from sports psychology, cognitive psychology and neuroscience. Moreover, accumulated data from different field of study will provide athletes with a set of effective instructions and procedures to employed imagery intervention. The PETTLEP imagery approach is different from traditional imagery as the model provides athletes with seven important elements during imagery training. Therefore, some researchers found that the PETTLEP model imagery is more effective than the traditional imagery (Koehn, Morris, \& Watt, 2014).

In relation to the application of element of physical and environment in PETTLEP imagery Morris, Spittle, and Watt, (2005), have suggested three types of technologies in imagery training such as video modeling, bio feedback and flotation which can be implemented. From all of these methods, video modelling is the best way to deliver imagery based on the PETTLEP requirement. Video modelling was found to be easier, more affordable and highly effective in applying imagery. In this method, an athlete needs to watch a video recording and translates a cognitive image video that they viewed into their own motor performance (Morris et al., 2005). If the model in the video recording is similar to the motor performance desired by the athlete, the athlete will be able to translate it more effectively.

In this study, the PETLEP model of imagery and the traditional imagery are two different interventions that will be examined to ensure the effect on performance. The PETTLEP model of imagery will be divided into two groups, which consist of the audio and the combination of audio video to deliver imagery. For traditional imagery script will be provided to research participant to be employed at their living place. Moreover, this traditional imaginary intervention will be carried out by the participants in according to the training schedule that given to them. Contrary, participant in the PETTLEP model imagery training will be provided with imagery with a similar situation as their training ground (Wakefield \& Smith, 2012). 
As imagery training was found to be able to improve the ways of athletes think, changing the perception of an athlete towards success and increasing their motivation was crucial in achieving the best performance of skills. Thus, this study was conducted to examine different effects of imagery training procedures to improve the shooting accuracy among netball players.

\section{METHODS}

\section{Participants}

Forty-eight netball players from four schools in Larut Matang and Selama, Perak Malaysia were invited to participate in this study voluntary. The participants of this study must have basic knowledge in netball. However, the participants of this study were screened after they had done the SIAM (Sport Imagery Ability Measure) test. They were screening for optimum SIAM Test scores and found suitable for this study. As according to Morris et al. (2005) an optimum level necessary to improve imagery abilities effectively is scores between 150 and 400 . This procedure was implemented to get homogenous participants for imagery ability.

\section{Design}

In this study the pre-test, intervention and post-test design were employed. The participants were divided into three groups that consist of the PETTLEP imagery audio, the PETTLEP imagery that combined audio and video and traditional imagery script interventions.

\section{Measures}

Demographic information. Participants' information that included age, weight, height, sport competitive level and years of experience in netball competition was provided using this demographic form.

Netball shooting performance. The participants performed netball shooting test at nine different positions and three trials were be given in each position. A replica of the defender player (heights 1.65 meters) made from plastics bunting was placed three feet ( 0.9 meters) from the position of the participants. This distance and replica heights were the actual distance allowed in the netball game when the defender wanted to block the opponent (Figure 1). 


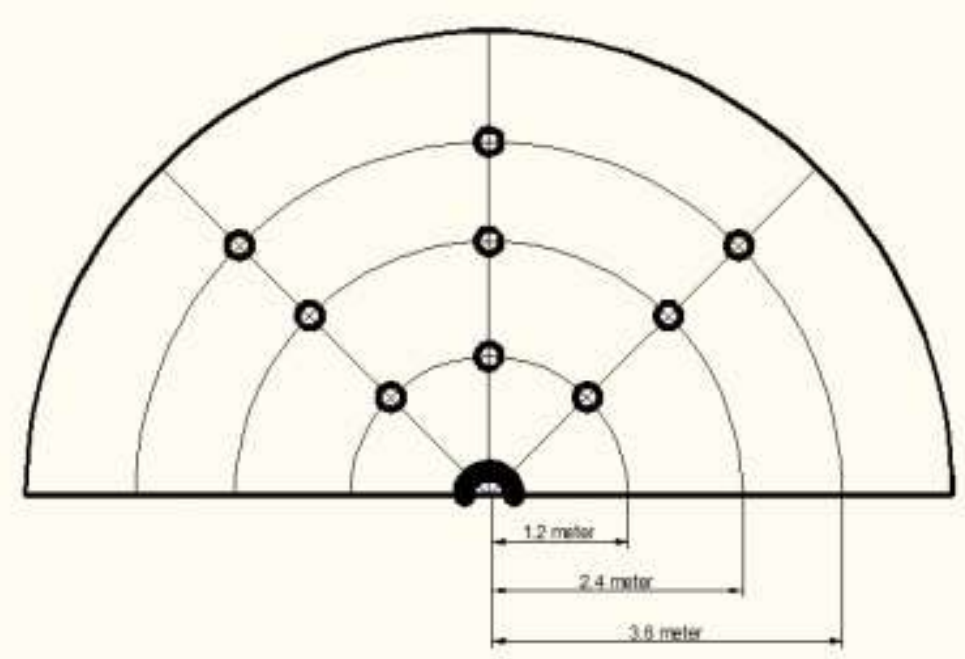

Figure 1: Plan for netball shooting accuracy test

Scores were given based on the accuracy of the shooting. Three points were awarded to the $100 \%$ full entry shooting regardless of any parts of the hoop and pillar. Two points were given for the ball that touched the hoop and goes in. One point was given to the ball which is touch the hoops and exits and 0 point was given for the ball out and not touching any hoops or pillars. The maximum points to be earned by each participant were 81 points (nine positions $\mathrm{x}$ three times trials $\mathrm{x}$ three points maximum) while the minimum score was 0 (Thariq Khan, 2013).

PETTLEP and Traditional Imagery. In the intervention phase, participants in the PETTLEP imagery audio and the PETTLEP imagery audio and video practices their imagery at the netball court before physical practice and wearing training attire. However, the participants in the traditional imagery group practiced their imagery in isolated classroom using imagery scripts. The LCD and speaker were used to deliver the imagery for participants in the PETTLEP audio imagery and PETTLEP audio and video imagery intervention. The participants in the imagery traditional group were provided with description and guides in written on how to perform traditional imagery and they needed to record all their imagery activities in the log book. For imagery interventions, the imagery guide provided to the participants was developed based on suggestions from two experts, a sports psychologist and netball coach. The imagery training script was based on performing a perfect netball shooting test and the timing was according to the real-time situation as in the netball shooting test. The participants conducted imagery training by implying that their shooting must be completed within three seconds as in real netball matches (Forlenza, Weinberg, and Horn (2014). The participants in PETTLEP audio and video imagery participants viewed an expert netball player video performing perfect netball shooting test from various angels and distances that had been downloaded from the 'You Tube' program. This video was edited using the 'Windows Movie Maker'. The interventions of all imagery were scheduled for 30 minutes per session for three times a week for four weeks. This dose of training as based from the suggestion 
of Wakefield and Smith (2009) stated that the effects of imagery could be seen due to the frequency of the imagery instead of the number of imagery performed.

\section{Procedures}

Research participants were guided by researcher to fill the demographic form before completing the SIAM test (Sport Imagery Ability Measure - Malay Version) to identify their imagery abilities. The pre-test was conducted and the participants were divided into three groups based on the imagery and shooting tests score to accommodate homogenous condition. All participants practiced imagery intervention for three times a week for four weeks before netball training. Posttest was conducted after all participants completed the four week imagery intervention.

\section{RESULTS}

\section{Demographic data}

All study participants were women. The participants mean weight was $50.88 \mathrm{~kg}$ and the height was 1.54 metre. The participants mean BMI was $21.44 \mathrm{~kg} / \mathrm{m}^{2}$ and mean age was 14.77 years.

\section{Netball shooting performance}

Table 1. Shooting Accuracy

\begin{tabular}{cccccc}
\hline & \multicolumn{2}{c}{ Pre } & \multicolumn{2}{c}{ Post } & \\
& Min & SD & Min & SD & Sig* $^{*}$ \\
\hline Traditional & 22.56 & 5.96 & 22.94 & 5.13 & 0.8 \\
Audio & 18.93 & 5.45 & 38.06 & 5.34 & $0.0^{*}$ \\
Audio Video & 20.06 & 4.61 & 50.88 & 4.75 & $0.0^{*}$ \\
\hline
\end{tabular}

Table 1 describes descriptive data comparison of shooting accuracy test for traditional imagery groups, PETTLEP imagery models audio and PETTLEP imagery model audio and video at pre and post-test levels in terms of Confidence Interval and standard deviation.

Employing the Paired Sample Analysis T-Test, the findings show that there is no significant difference in intervention effects among the participants in traditional imagery groups comparing the pre and post-test shooting performance results. Conversely, there are significant difference among participants of imagery group of PETTLEP imagery model audio and PETTLEP imagery model audio and video comparing the pre and post-test shooting performance results $(\mathrm{p}<0.05)$.

The One Way ANOVA results comparing research participants of post-test shooting performance between group showed that there were significant differences between the Traditional and Audio participant, and between the Traditional and Audio Video group $(\mathrm{p}<0.05)$. However, 
there is no significant difference between groups among the participants in Audio compared to Audio Video group.

Table 2. One Way ANOVA Score for shooting accuracy

\begin{tabular}{|c|c|}
\hline & Shooting accuracy \\
\hline & Sig \\
\hline Traditional and Audio & $0.0^{*}$ \\
Audional and Audio Video & $0.0^{*}$ \\
\hline
\end{tabular}

Table 2 describes descriptive data comparing shooting accuracy for traditional imagery groups, PETTLEP imagery model audio and PETTLEP imagery model audio and video in terms of $\mathrm{p}$ grade level using the One Way ANOVA test.

\section{DISCUSSIONS}

The main purpose of this study was to identify the effectiveness of traditional imagery, PETTLEP imagery model audio and PETTLEP imagery model audio and video in shooting accuracy for netball players in Larut Matang and Selama district. Thus, participants' performance was analyzed and compared with previous study results. Based on the findings, there was a statistically significant difference between the pre-test and the post-test $(\mathrm{p}<0.05)$ for the three intervention groups for the shooting accuracy test. The PETTLEP model imagery audio and video group showed the main effects and the highest scores over the traditional imagery group as well as the PETTLEP imagery model audio in shooting accuracy. For traditional imagery group scores, there was no significant difference $(\mathrm{p}>0.05)$.

This shows that the PETTLEP audio and audio video PETTLEP interventions provided better performance improvement compared to the traditional written scripts imagery group. In this study, video modeling was used as an additional tool to deliver the information of a particular skill more clearly, and this perhaps, facilitates the study participants to imitate the behavior as shown by the model in the video and assisted with the use of audio.

This study results were parallel to Holmes and Collins, (2001) suggestions that the PETTLEP Imagery Model should consist of seven elements (Physical, Environment, Task, Time, Learning, Emotion and Perspective). Most probably by providing athlete with these audio video imagery they learned something from video modeling and provide attention by observing the model in the video before imagery training. The empirical evidence show that previous studies have pointed out that imagery is the most effective psychological method in improving the performance of 
athletes in sports (Holmes \& Collins 2001). In this study, researchers have incorporated the PETTLEP imagery model with audio and also audio and video to provide similar physical, environment, task time and learning perspectives. Moreover, in audio imagery, the element of emotion and the other elements were included. The use of all elements was expected to provide better chances for athletes to get an optimum benefits from imagery training. Conversely, participants of the traditional imagery script intervention demonstrated a less significant improvement. Even though, the imagery scripts provided to the participants in this study was similar to the PETTLEP groups, the performance improvement was lower compare to PETTLEP imagery groups. If the audio and video medium of imagery training was taken into consideration compared to traditional written imagery script, perhaps, imagery will be more effective if the athlete feels easy to do the imagery.

In conclusion, this study suggests that video image PETTLEP imagery interventions are more beneficial on the improvement of shooting accuracy test. The traditional imagery has not given a significant improvement on the shooting accuracy test for the netball players in Larut Matang and Selama district. The methodology of this study carried out was simple, compact and attracted the participants as it was easy for them to understand the types or skills that they needed to improve their shooting accuracy. This has also been explained by Rymal et al. (2010) that prerecorded imagery scripts that are also equipped with video-modeling can provide an athlete with relevant information on the exercise of a sports skill that can lead to performance improvement.

Imagery of this PETTLEP model audio and video can be used as a useful tool for school, district and state netball coaches to conduct training in order to improve the shooting accuracy of the netball players. However, extensive and wider research is needed to support the impact of PETTLEP's imagery model for different skills. Researchers suggest that future studies may be able to carry out PETTLEP imagery intervals in a longer term. The study is likely to be more meaningful because the time spent can be utilized for participants to better understand how imagery can give a maximum impact on their users. In addition, imagery of PETTLEP model of video and audio can be carried out to see the difference between elite athletes and novice athletes as neural imagination studies have shown that neutral networks are activated by different mental imagery between novice and elite athlete (Buck et al., 2016). The videos and audio added in the PETTLEP model imagery are useful to athletes who have difficulty generating, maintaining and controlling their mental imagery.

\section{REFERENCES}

Buck, D., Hutchinson, J., Winter, C., \& Thompson, B. (2016). The Effects of Mental Imagery with VideoModeling on Self-Efficacy and Maximal Front Squat Ability. Sports, 4(23), 1-10. http://doi.org/10.3390/sports4020023

Forlenza, S. T., Weinberg, R. S., \& Horn, T. S. (2014). Imagery speed and self-efficacy : how fast (or slow) to go? International Journal of Golf Science, 2(2), 126-141. doi:10.1123/ijgs.2013-0012 
Holmes, P.S., \& Collins, D.J (2001). The PETTLEP approach to motor imagery : A functional equivalanece model for sport psychologists. A Journal of Applied Sport Psychology, 13, 60-83.

Koehn, S., Morris, T., \& Watt, A. P. (2014). Imagery Intervention to Increase Flow State and Performance in Competition. The Sport Psychologist, (2002), 48-59. http://doi.org/10.1123/tsp.2012-0106

Morris, T., Spittle, M., \& P.Watt, A. (2005). Imagery in sport. United States of America: Human Kinetics.

Nordin, S.M., \& Cumming, J. (2008). Types and functions of athletes' imagery: Testing predictions from the Applied Model of Imagery Use by examining effectiveness. International Journal of Sport and Exercise Psychology, 6, 189-206. doi:10.1080/1612197X.2008.9671861

Rymal, A., Martini, R., \& Ste-Marie, D. . (2010). Self-regulatory processess employed during selfmodelling: A qualitative analysis. Sport Psychologist, 24(1), 1-15.

Short, S.E., Bruggeman, J.M., Engel, S.G., Marback, T.L., Wang, L.J., Willadsen, A., \& Short, M.W. (2002). The effect of imagery function and imagery direction on Imagery Speed and Self-Efficacy 141 self-efficacy and performance on a golf-putting task. The Sport Psychologist, 16, 48-67.

Thariq Khan Azizuddin Khan. (2013). Portable devices to deliver imagery in sport: effects on athletes sport performance and self-efficacy. Victoria University.

Vealey, R.S., \& Greenleaf, C.A. (2009). Seeing is believing: Understanding and using imagery in sport. In J.M. Williams (Ed.), Applied sport psychology: Personal growth to peak performance (6th ed., pp. 267-304). New York, NY: McGraw-Hill

Wakefield, C. J., \& Smith, D. (2009). Impact of Differing Frequencies of PETTLEP Imagery on Netball Shooting Performance. Journal of Imagery Research in Sport and Physical Activity, 4(1). http://doi.org/10.2202/1932-0191.1043

Wakefield, C., \& Smith, D. (2012). Perfecting practice: applying the PETTLEP model of motor imagery. Journal of Sport Psychology in Action, 3(1), 1-11. http://doi.org/10.1080/21520704.2011.639853

¡ Thariq Khan Azizuddin Khan

Fakulti Sains Sukan dan Kejurulatihan, Universiti Pendidikan Sultan Idris, 35900 Tanjung Malim, Perak,

Malaysia

Email: thariq@fsskj.upsi.edu.my 